\title{
The Evaluation of Early Results after Total Hip Replacement in Dysplastic Hip Patients
}

\author{
Silvestris Zebolds*, Andris Jumtins** \\ * State Hospital of Traumatology and Orthopaedics, Riga, Latvia \\ **Riga Stradins University, Riga, Latvia
}

\begin{abstract}
Summary
Introduction. Dysplasia of hip joint leads to osteoarthritis. Suffer relatively young population in ages between 20 and 40 . Due to severe changes of anatomy total hip replacement (THR) in dysplastic hip patients is a challenge for orthopaedic surgeons. Radical anatomical and biomechanical reconstruction may lead to high complication rate. The planning of the rotation center of hip joint is a key of success in the treatment of dysplastic osteoarthritis patients.

Aim of the Study. The aim of the study was to evaluate the early results for dysplastic osteoarthritis patients (DOA), who underwent THR in Riga State Hospital of Traumatology and Orthopaedics in 2008-2009.

Materials and methods. 63 THR were performed in 59 patients ( 50 women, 9 men). In all cases cementless acetabular components of endoprosthesis were used. Functional evaluation was made due to method of grading functional value of hip - Merle d'Aubigne and Postel. Hip dysplasia was divided in 4 groups due to classification after Crowe. Special digital orthopaedic programmes (AGFA, IMPAX) were used for preoperative planning and radiographic postoperative analysis.

Results. Regarding to method of grading functional value of hip - Merle d'Aubigne and Postel we found out a significant improvement in range of movements, mobility and pain relief. Due to Crowe classification there were 19 patients with Crowe type I dysplasia, 29 with Crowe type II and 15 with Crowe type III. 43 acetabular cups were placed in the primary socket and 20 in the secondary socket. Radiographic analysis showed significant changes in location of rotation center of hip and offset after THR in dysplastic hip patients. Conclusions. Significant functional improvement was achieved after THR in DOA patients and the radiographic analysis showed significant decrease of horizontal location of RC and increase of offset after THR in DOA patients.
\end{abstract}

Key words: dysplastic osteoarthritis, rotation center of hip joint, digital planning.

\section{INTRODUCTION}

The abnormal loading of joint cartilage leads to developing of osteoarthritis in patients with hip dysplasia. Patients are relatively young and mostly women between the ages of 20 and 40 . The signs of osteoarthritis are strongly associated with increasing age and the severity of dysplasia (4). In our study we used classification after Crowe (1). Total hip replacement (THR) in dysplastic hip patients is a challenging procedure. Anatomy of the joint is extremely changed in comparison with normal or primary osteoarthritic hip. Biomechanics of the hip joint, pelvis, lumbar spine and lower extremeties are often severly changed during the life time. Complication rate after THR in dysplastic hip patients is much more higher (3). Anatomical socket placement can result in a hip that is difficult to reduce, and reduction can be associated with considerable limb lengthening and an increased risk of neurological traction injury (6). Radical anatomical and biomechanical reconstruction of hip joint during operation may lead not only to local complications as overstretching of N.ischiadicus, contracture of hip joint, early loosening and wear of acetabular component of endoprosthesis, but even to the distress of the whole musculo-skeletal apparatus. For that reason it is very important to plan the best location of the acetabular cup, which depends on the chosen level of the rotation center of the hip joint.
Since 2008 in the Riga State Hospital of Traumatology and Orthopaedics (SHTO) we have a possibility to use special digital orthopaedic programms (AGFA, IMPAX) for radiographic preoperative planning and for analysing of postoperative results. 63 THR were performed in 59 dysplastic osteoarthritis patients during 2-years period (2008 and 2009) in Riga SHTO. All patients were clinically and radiographically examined before and after (follow up 3 to 27 months) operation. In addition questionnaires based on the modified method of grading functional value of hip after Merle d' Aubigne and Postel (8) were sent to all patients.

\section{AIM OF THE STUDY}

The aim of our study was to evaluate functional and radiographic outcomes after THR in dysplastic hip patients.

\section{MATERIALS AND METHODS}

All dysplastic osteoarthritis (DOA) patients who underwent THR in 2008 and 2009 in Riga SHTO were included in our study. In all 63 THR cases uncemented acetabular components of endoprosthesis were used. The distribution of acetabular components (cups): Duraloc used in 41 cases, W.Link T.O.P. - in 11 cases; Bicon Pluss - in 10 cases, BHR - in 1 case. 55 uncemented femoral components (stems) were used: SLPluss in 54 
and Nanos(short stem) in 1 case. Also 8 cemented stems were used: CSPluss - in 6 cases, W.Link LCP - in 2 cases. We applied Crowe classification to divide dysplasia in 4 types due to subluxation of the femoral head:

- Crowe - type I - subluxation less than 50\% (see figure 1);

- $\quad$ Crowe - type II - subluxation 50\% -75\% ;

- Crowe - type III - subluxation 75\%-100\% (see figure 5);

- Crowe-type IV - subluxation more than $100 \%$.

For evaluation of functional outcome we applied method of grading functional value of hip after Merle d'Aubigne and Postel (8). This method includes evaluation of patients due to 3 criteria: pain, function and mobility (Table 1).

Table 1. Method of grading functional value of hip Merle d'Aubigne and Postel

\begin{tabular}{|c|c|c|c|}
\hline $\begin{array}{c}\text { Gra- } \\
\text { de }\end{array}$ & Pain & Function & Mobility \\
\hline 0 & $\begin{array}{l}\text { Pain is intense } \\
\text { and permanent }\end{array}$ & $\begin{array}{l}\text { Ankylosis with } \\
\text { bad position of } \\
\text { hip }\end{array}$ & None \\
\hline 1 & $\begin{array}{l}\text { Pain is severe } \\
\text { even at night }\end{array}$ & $\begin{array}{c}\text { No } \\
\text { movenent;pain } \\
\text { or slight } \\
\text { deformity }\end{array}$ & $\begin{array}{l}\text { Only with } \\
\text { crutches }\end{array}$ \\
\hline 2 & $\begin{array}{c}\text { Pain is severe } \\
\text { when walking; } \\
\text { prevents any } \\
\text { activity }\end{array}$ & $\begin{array}{c}\text { Flexion under } 40 \\
\text { degrees }\end{array}$ & $\begin{array}{l}\text { Only with } \\
\text { canes }\end{array}$ \\
\hline 3 & $\begin{array}{c}\text { Pain is tolerable } \\
\text { with limited } \\
\text { activity }\end{array}$ & $\begin{array}{c}\text { Flexion between } \\
40 \text { and } 60 \\
\text { degrees }\end{array}$ & $\begin{array}{c}\text { With one } \\
\text { cane, less } \\
\text { than l hour; } \\
\text { very difficult } \\
\text { without cane }\end{array}$ \\
\hline 4 & $\begin{array}{c}\text { Pain is mild } \\
\text { when walking; } \\
\text { disappears with } \\
\text { rest }\end{array}$ & $\begin{array}{c}\text { Flexion between } \\
60 \text { and } 80 \\
\text { degrees; patient } \\
\text { can reach his } \\
\text { foot }\end{array}$ & $\begin{array}{l}\text { A long time } \\
\text { with a cane; } \\
\text { short time } \\
\text { without cane } \\
\text { and with } \\
\text { limp } \\
\end{array}$ \\
\hline 5 & $\begin{array}{l}\text { Pain is mild } \\
\text { and inconstant; } \\
\text { normal activity }\end{array}$ & $\begin{array}{c}\text { Flexion } \\
\text { between } 80 \\
\text { and } 90 \text { degrees; } \\
\text { abduction of at } \\
\text { least } 15 \text { degrees }\end{array}$ & $\begin{array}{l}\text { Without cane } \\
\text { but with } \\
\text { slight limp }\end{array}$ \\
\hline 6 & No pain & $\begin{array}{c}\text { Flexion of more } \\
\text { than } 90 \text { degrees; } \\
\text { abduction to } 30 \\
\text { degrees }\end{array}$ & Normal \\
\hline
\end{tabular}

The worst score is 0 points - for a patient with permanent pain, no movement and bad position of the hip, walking is not possible. The best score is 6 points in each group, it means it is possible to achieve result of maximum 18 points-for a patient with no pain (6 points in pain score), flexion in hip joint more than 90 degrees ( 6 points in function score), normal walking ( 6 points in mobility score).

Special orthopaedic programmes (AGFA,IMPAX) were used for preoperative planning and postoperative evaluation of radiographs. Metallic ball marker of known diameter $(25 \mathrm{~mm})$ was used for calibration of the radiograph in $\mathrm{A}-\mathrm{P}$ projection. The rotation center of the hip joint is similar with the center of the head of the femur (point A in figure 1) or center of the head of endoprosthesis after THR (point A in figure 2).

Fig. 1. Preoperative measurements in A-P radiograph - Crowe-type I dysplastic OA of the right hip joint (AB-the vertical location of the rotation center; $A C$-the horizontal location of the rotation center; AD- the offset; angle FAE- Wiberg lateral center edge angle)

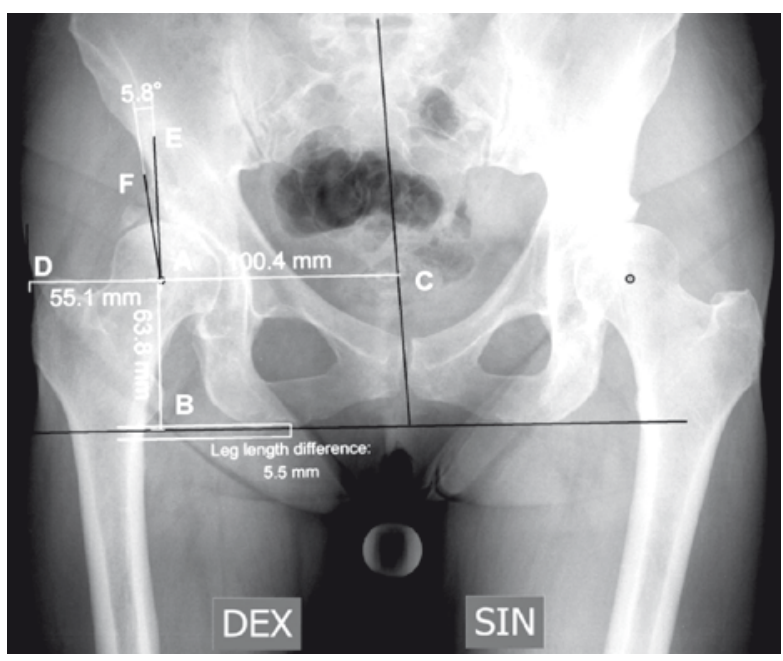




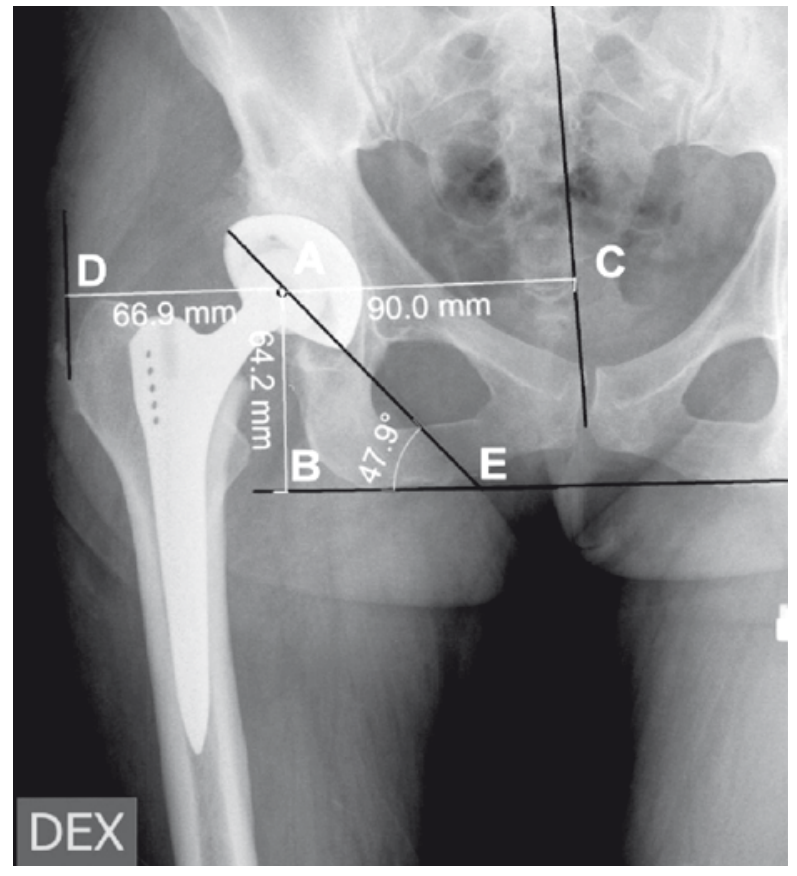

Fig. 2. Postoperative measurements in A-P radiograph- THR of the right hip joint with uncemented EP(W.Link T.O.P. acetabular component of endoprosthesis located into the primary socket,SLPluss stem and ceramic ball head used; $\mathrm{AB}$-the vertical location of the rotation center of the hip joint, AC- the horizontal location of the rotation center of the hip joint; $A D-$ the offset; angle AEB- the inclination angle of the acetabular component of endoprosthesis into the pelvis)

Postoperatively we analysed the placement of acetabular component. If the rotation center of the endoprosthesis was similar with the anatomic hip center, we considered that acetabular cup is placed in the primary socket (figure 2). If the rotation center of endoprosthesis was placed more than $1 \mathrm{~cm}$ cranially, then we considered that the cup is placed in the secondary socket (figure 6). We used 3 main measurements for evaluation of the location of the rotation center of hip joint: vertical location - the distance from the ischial tuberosity to the center of the femoral head (distance $A B$, see figure 1); horizontal location - the distance from the line, which connects processus spinosus of lumbar spine with the center of symphysis to the center of the femoral head (distance AC, see figure 1). The third measurement is Wiberg lateral center edge angle (CEA) which is the angle between vertical line from the center of the femoral head and line which connects the center of the femoral head and lateral edge of the acetabulum (angle FAE in figure 1). Usually Wiberg lateral edge angle in dysplastic hip patients is less than 25 degrees and depends on the severity of dysplasia $(7,9)$. For abductor muscle tension the offset is important. It is the distance from the center of the femoral head to the lateral edge of greater trochanter (distance $\mathrm{AD}$ in figure 1). To evaluate postoperative radiographic changes in the location of rotation center of hip joint we measured vertical and horizontal location of the center of the head of endoprosthesis. We compared the planned location of rotation center of the hip joint, inclination angle and size of the acetabular component with postoperative outcome (figure 2,5,6). For evaluation of leg length descrepancy we measured and compared distances from lesser trochanters to the line that connects both ischial tuberosities.

\section{RESULTS}

63 THR were performed in 2 years period in 59 patients. 50 patients were women and $9-$ men. Mean age was 45,30 (from 20 to74) years. From 59 sent questionnaires we received 40 responses $(68 \%)$. The follow-up was 3 to 27 month after THR. According to method of grading functional value of hip - after Merle d Aubigne and Postel the pain score (in average) increased from 1,30 preoperatively to 5,70 postoperatively (nearly all patient were free of pain after THR). The function score changed from 3,30 to 5,60 and the mobility score also increased from 3,30 to 5,30 points (figure 3).

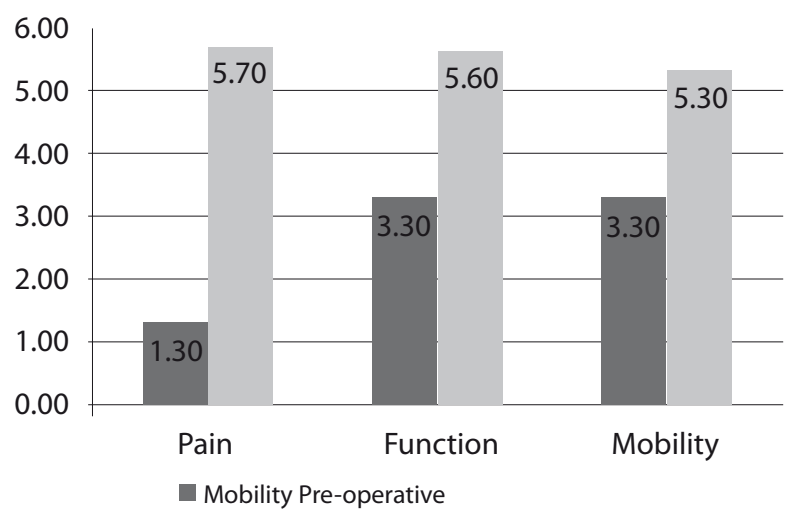

Fig. 3. The evaluation of funcional result pre- and postoperatively according to Merle $d^{\prime}$ Aubigne and Postel grading system

Distribution of patients due to severity of dysplasia $(n=63$ THR): Crowe - type I - 19, Crowe - type II - 29, Crowe type III - 15. We did not have Crowe- type IV patients in 2008 and 2009. Postoperative analysis showed us that in 43 cases the acetabular cup was placed at the anatomical site (in the primary socket), but in 20 cases in the secondary socket. In all Crowe - type I dysplasia cases (19) the cups were operated in the primary socket, from 29 Crowe - type II dysplasia cases 22 were placed in primary, but 7 in secondary socket. From 15 Crowe type III dysplasia cases 2 cups were placed in primary, 13 in secondary socket (Figure 4). 


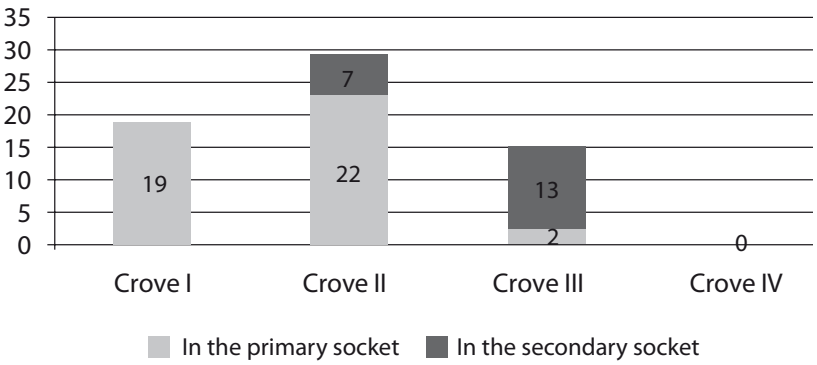

Fig. 4. Distribution of dysplasia due to Crowe classification, placement of acetabular components in the primary or secondary sockets

Digital radiographic measurements were made for group of 23 patients. The analysis showed the following results after THR: average increase of the vertical location of the rotation center $(\mathrm{RC})$ was $2,5 \mathrm{~mm}(p=0.03)$, average decrease of the horizontal location of the rotation center was $7,5 \mathrm{~mm}(\mathrm{p}<0.001)$, average increase of the offset was $13,5 \mathrm{~mm}(\mathrm{p}<0.001)$, see table 2 . The decrease of horizontal RC can be explained by medialization of acetabular component therefore satisfactory bone coverage of cup was obtained during THR. The offset increase is very important for abductor muscle function as well as the adequate tension of abductors ensures the stability of the hip joint. The increase of the offset depends on the length of the modular necks of the femoral component of endoprosthesis.

Table 2. Change of the rotation center of the hip joint and offset after total hip replacement (THR)

\begin{tabular}{|c|c|c|}
\hline & Before THR & After THR \\
\hline $\begin{array}{l}\text { The vertical location } \\
\text { of the rotation } \\
\text { center(average) }\end{array}$ & $\begin{array}{l}61,9 \\
(\min 30,4 \mathrm{~mm} ; \\
\max 77,5 \mathrm{~mm})\end{array}$ & $\begin{array}{l}64,4 \mathrm{~mm} \\
(\min 41,5 \mathrm{~mm} ; \\
\max 75,8 \mathrm{~mm})\end{array}$ \\
\hline $\begin{array}{l}\text { The horizontal } \\
\text { location of the } \\
\text { rotation center } \\
\text { (average) }\end{array}$ & $\begin{array}{l}99,6 \mathrm{~mm} \\
(\min 72,3 \mathrm{~mm} ; \\
\max 118,9 \\
\mathrm{~mm})\end{array}$ & $\begin{array}{l}92,1 \mathrm{~mm} \\
(\min 76,4 \mathrm{~mm} ; \\
\max 97,8 \mathrm{~mm})\end{array}$ \\
\hline Offset (average) & $\begin{array}{l}49,7 \mathrm{~mm} \\
(\min 30,0 \mathrm{~mm} ; \\
\max 69,2 \mathrm{~mm})\end{array}$ & $\begin{array}{l}63,3 \mathrm{~mm} \\
(\min 49,6 \mathrm{~mm} ; \\
\max 80,7 \mathrm{~mm})\end{array}$ \\
\hline
\end{tabular}

We compared also the the planned vertical location of $\mathrm{RC}$ of hip joint with postoperative result. The mean difference was $0,8 \mathrm{~mm}$ (not significant). The planned inclination angle of the acetabular cup was about 44 degrees, but postoperative angle of inclination was 38,5 degrees (Table 3). So significant difference could be explained by try of surgeons to locate the acetabular cups more horizontally for reducing the risks of luxation.
Table 3. The comparison of the planned position of the rotation center of endoprosthesis and inclination angle of acetabular component with the postoperative result

\begin{tabular}{|c|c|c|}
\hline & $\begin{array}{l}\text { Preoperative } \\
\text { planning }\end{array}$ & $\begin{array}{l}\text { Postoperative } \\
\text { result }\end{array}$ \\
\hline $\begin{array}{l}\text { The vertical } \\
\text { location of } \\
\text { the rotation } \\
\text { center(average) }\end{array}$ & $\begin{array}{l}65,2 \mathrm{~mm} \\
(\min 52,0 \mathrm{~mm} ; \\
\max 75,6 \mathrm{~mm})\end{array}$ & $\begin{array}{l}64,4 \mathrm{~mm} \\
(\mathrm{~min} 41,5 \\
\mathrm{mm} ; \max 75,8 \\
\mathrm{~mm})\end{array}$ \\
\hline $\begin{array}{l}\text { The inclination } \\
\text { angle (average) }\end{array}$ & $\begin{array}{l}44,4^{\circ} \\
\left(\min 31,2^{\circ} ; \max \right. \\
\left.49,9^{\circ}\right)\end{array}$ & $\begin{array}{l}38,5^{\circ} \\
\left(\min 24,7^{\circ}\right. \\
\left.\max 52,6^{\circ}\right)\end{array}$ \\
\hline
\end{tabular}

The average Wiberg lateral CEA was $17.9^{\circ}$ (min 0 degrees, max 42.9 degrees).In cases with CEA bigger than 25 degrees, DOA patients usually had collapsed femoral heads due to aseptic necrosis.The sizes of implants were planned precisely. The mean difference was only $0,2 \mathrm{~mm}$ ( not significant). In our study we did not see any major complications as dislocations, infections, early loosening of components of endoprosthesis etc.

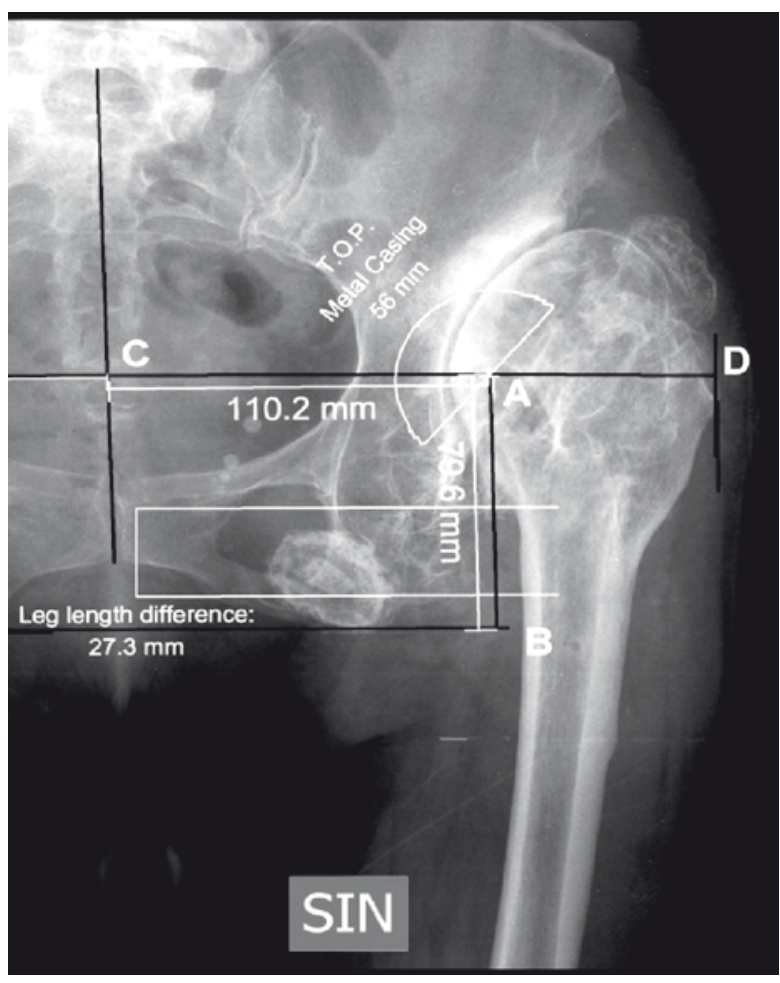

Fig. 5. A-P radiograph of the pelvis- Crowe -type III dysplastic $O A$ of the left hip joint(point Athe planned rotation center of the hip joint after THR;AB- the planned location of the vertical RC; AC-the planned location of the horizontal RC ) 


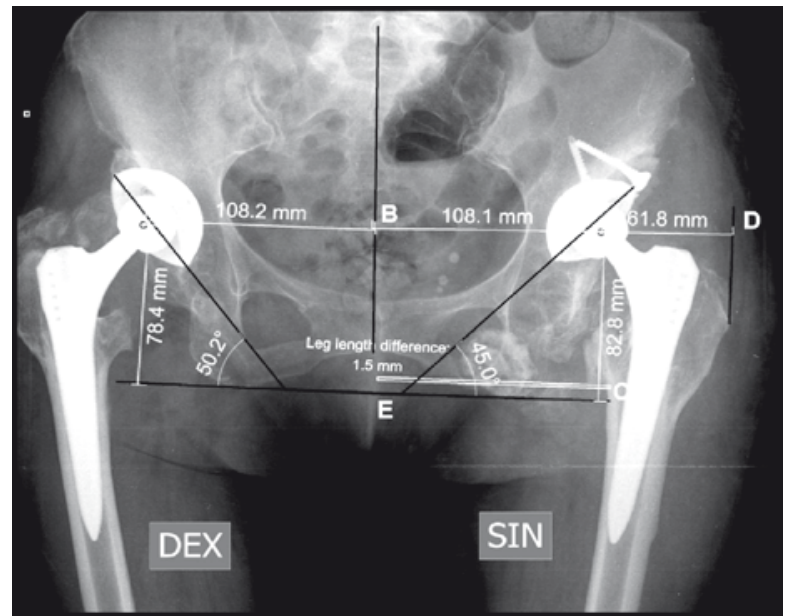

Fig. 6. A-P radiograph of the pelvis- THR of both hip joints with uncemented EP(W.Link uncemented T.O.P. acetabular components located into the secondary sockets, bone grafting of the roof of the left acetabulum is made for better coverage of the cup, uncemented SLPluss stems and metal ball heads used;point $A$-the rotation center of the left hip joint;AB-the horizontal location of RC;AC-the vertical location of RC;ADthe offset;angle AEC-the inclination angle of acetabular component into the pelvis)

\section{DISCUSSION}

Due to changed anatomy the complication rate in DOA patients (Crowe - typeII, III, IV ) is much more higher than in degenerative OA patients. For patients with dysplasia Crowe - typeIV major complication rate can reach even $43 \%$ (Krych,2009). The most common cause (about 33\%) for acetabular revision is instability or dislocation (Bozic,2009).The radical anatomical and biomechanical reconstruction of the hip joint during THR and trying always to place the acetabular component at the level of anatomic hip center may lead to limb lengthening, neurological injury and early cup loosening.In our study 20 cups (32\%) were placed in secondary socket and we did not see any major complications. We consider that preoperative planning of the location of the RC of hip joint due to grade of dysplasia is a key of success for treatment of DOA patients.

\section{CONCLUSIONS}

1. Significant functional improvement and pain relief were achieved after THR in DOA patients in shortterm follow-up.

2. The radiographic analysis showed decrease of the horizontal location of the center of rotation of the hip joint and increase of the offset after THR in DOA patients, but there were no significant changes in the vertical location of the rotation center.
Conflict of interest: None

\section{REFERENCES}

1. Crowe J.F., Many V.J., Ranawat C.S. Total hip replacemet in congenital dislocation of the hip // JBJS, 1979; 61A: $15-23$.

2. Bozic K.I., Kurtz S.M., Lau E. Et al., Theepidemiology of revisiontotal hip aarthroplastyin the United States //JBJS Am. 2009;91:128-33.

3. Hendrich C., Engelmaier F., Mehling I., et al. Cementless acetabular reconstruction and structural bone-grafting in dysplastic hips. Surgical tecnique // JBJS, 2007; 89: $54-67$.

4. Jessel R.H., Zurakowski D., Zilkens C. et. al. Radiographic and patient factors associated with pre-radiographic osteoarthritis in hip dysplasia // JBJS Am., 2009; 91:1120 - 1129.

5. Klapach A.S., Callaghan J.J., Miller K.A., et.al. Total hip arthroplasty with cement and without acetabular bone graft for severe hip dysplasia// JBJS Am., 2005;87:280 -285.

6. Krych A.J., Howard J.L., Trousdale R.T., et.al. Total hip arthroplasty with shortening subtrochanteric osteotomy in Crowe Type-IV developmental dysplasia // JBJS Am., 2009; 91: 2213 - 2221.

7. Maeyama A., Naito M., , Moriyama S., Yoshimura I. Evaluation of dynamic instability of the dysplastic hip with use of triaxial accelerometry // JBJS Am., 2008;90:85-9/

8. Merle d' Aubigne R., Postel M., Functional results of hip arthroplasty with acrylic prosthesis // JBJS, 1954; 36: 45.

9. Wiberg G. Studies of dysplastic acetabula and congenital subluxation of the hip joint. With special reference to complication of osteoarthritis // Acta Chir.Scand., 1939; 58(Suppl):5-135.

\section{Address:}

Silvestris Zebolds

State Hospital of Traumatology and Orthopaedics,

Riga, Latvia

Duntes street 22 Riga, Latvia LV-1005

E-mail: szebolds@apollo.lv 